Article

\title{
Investigation of Long COVID Prevalence and Its Relationship to Epstein-Barr Virus Reactivation
}

\author{
Jeffrey E. Gold ${ }^{1, *}$, Ramazan A. Okyay ${ }^{2}$, Warren E. Licht ${ }^{3}$ and David J. Hurley ${ }^{4}$ \\ 1 World Organization, Watkinsville, GA 30677, USA \\ 2 Department of Public Health, Kahramanmaraş Sütçü İmam University, Kahramanmaraş 46040, Turkey; \\ razim01@gmail.com \\ 3 Warren Alpert Medical School of Brown University, Providence, RI 02903, USA; \\ warren.licht@brownphysicians.org \\ 4 College of Veterinary Medicine, University of Georgia, Athens, GA 30602, USA; djhurley@uga.edu \\ * Correspondence: jeff_gold@world.org
}

Citation: Gold, J.E.; Okyay, R.A.; Licht, W.E.; Hurley, D.J. Investigation of Long COVID Prevalence and Its Relationship to Epstein-Barr Virus Reactivation. Pathogens 2021, 10, 763. https://doi.org/10.3390/ pathogens 10060763

Academic Editor: Lisa Gralinski

Received: 26 May 2021

Accepted: 12 June 2021

Published: 17 June 2021

Publisher's Note: MDPI stays neutral with regard to jurisdictional claims in published maps and institutional affiliations.

Copyright: (C) 2021 by the authors. Licensee MDPI, Basel, Switzerland. This article is an open access article distributed under the terms and conditions of the Creative Commons Attribution (CC BY) license (https:/ / creativecommons.org/licenses/by/ $4.0 /)$.

\begin{abstract}
Coronavirus disease 2019 (COVID-19) patients sometimes experience long-term symptoms following resolution of acute disease, including fatigue, brain fog, and rashes. Collectively these have become known as long COVID. Our aim was to first determine long COVID prevalence in 185 randomly surveyed COVID-19 patients and, subsequently, to determine if there was an association between occurrence of long COVID symptoms and reactivation of Epstein-Barr virus (EBV) in 68 COVID-19 patients recruited from those surveyed. We found the prevalence of long COVID symptoms to be $30.3 \%$ (56/185), which included 4 initially asymptomatic COVID-19 patients who later developed long COVID symptoms. Next, we found that $66.7 \%(20 / 30)$ of long COVID subjects versus $10 \%(2 / 20)$ of control subjects in our primary study group were positive for EBV reactivation based on positive titers for EBV early antigen-diffuse (EA-D) IgG or EBV viral capsid antigen (VCA) $\operatorname{IgM}$. The difference was significant ( $p<0.001$, Fisher's exact test). A similar ratio was observed in a secondary group of 18 subjects 21-90 days after testing positive for COVID-19, indicating reactivation may occur soon after or concurrently with COVID-19 infection. These findings suggest that many long COVID symptoms may not be a direct result of the SARS-CoV-2 virus but may be the result of COVID-19 inflammation-induced EBV reactivation.
\end{abstract}

Keywords: long COVID; post-acute COVID-19 syndrome; PACS; chronic COVID syndrome; EpsteinBarr virus reactivation; Epstein-Barr virus; EBV; SARS-CoV-2; COVID-19; coronavirus

\section{Introduction}

It has been reported that about $30 \%$ of coronavirus disease 2019 (COVID-19) patients experience long-term symptoms following resolution of acute disease [1]. These symptoms include fatigue, brain fog, sleep difficulties, arthralgia, pharyngitis, myalgia, headaches, fever, gastrointestinal upset, and skin rashes with a variety of presentations [2-5]. Longterm symptoms associated with COVID-19 are collectively known as long COVID. Long COVID has also been referred to as Post-Acute COVID-19 Syndrome (PACS) or chronic COVID syndrome (CCS) [6]. Long COVID has been associated with patients who have had subacute, mild, or severe COVID-19 cases [2].

Epstein-Barr virus (EBV) is a human gamma herpesvirus. It is known to have infected and generally become latent in more than $90 \%$ of the global population [7], including more than $95 \%$ of healthy adults [8]. It is found at high rates in every region of the world. This is due to both its lifelong persistence in the latent state and because of its intermittent recrudescence in many latently infected individuals [9]. Primary EBV infection is often asymptomatic when contracted in childhood. When primary infection occurs in adolescence or adulthood, however, it commonly results in infectious mononucleosis, an acute condition inducing massive lymphocytosis. EBV sometimes causes chronic infections 
or serially reactivated infections, in which it can efficiently infect both epithelial cells and B cells. EBV can also switch between lytic and latent phases of its life cycles in many patients [10].

EBV reactivation is most commonly identified in clinical practice using serological testing for the presence of EBV early antigen-diffuse (EA-D) IgG or EBV viral capsid antigen (VCA) IgM [11-13]. EBV VCA IgM is usually only detectable during the acute early stage of primary or reactivated EBV infection. In contrast, EBV EA-D is more likely to be detected only during the later chronic stage of EBV infection [14]. Therefore, multiple testing methods are required to accurately detect EBV reactivation.

A variety of clinical manifestations have been associated with EBV reactivation. These include fatigue, psychoneurosis/brain fog, sleep disturbance, arthralgia, pharyngitis, myalgia, headaches, fever, gastrointestinal complaints, and various skin rashes [11]. We observed that many symptoms attributed to long COVID are the same as, or very similar to, those that have been associated with EBV reactivation.

Our aim in this retrospective study was to first determine long COVID prevalence among COVID-19 patients surveyed and, subsequently, to determine if there was evidence of a relationship between occurrence of long COVID symptoms and EBV reactivation among the subjects recruited from those surveyed.

\section{Results}

\subsection{Long COVID Prevalence}

An analysis of the 185 subjects who applied to our study, all of whom provided evidence of confirmed COVID-19 infections, revealed that 30.3\% (56/185) reported unabating long COVID symptoms at least 30 days after testing positive for COVID-19. This group included 13 subjects who had initially asymptomatic COVID-19 infections, among which $30.8 \%$ (4/13) went on to develop long COVID symptoms a few weeks after testing positive for COVID-19. Applicants were not aware of our intent to study long COVID. This blinding of the study subjects limited self-selection bias in the reporting of long COVID symptoms. The prevalence rate we observed was similar to the $30 \%$ prevalence rate observed in a University of Washington survey of 177 COVID-19 subjects followed for several months after their initial COVID-19 diagnosis [1].

\subsection{Analysis of Primary (Long-Term) Study Participants}

We found that $66.7 \%(20 / 30)$ of long-term long COVID subjects versus $10 \%(2 / 20)$ of long-term control subjects were positive for EBV reactivation based on positive titers for EBV EA-D IgG or EBV VCA IgM. The difference in the fraction showing reactivation between the groups was found to be significant $(p<0.001$, Fisher's exact test). Eighteen of the long-term long COVID subjects were positive for EBV EA-D IgG, one of which was also positive for EBV VCA IgM. Two additional long-term long COVID subjects were positive for EBV VCA IgM but not EBV EA-D IgG. Notably, two long-term long COVID subjects who were positive for EBV reactivation had asymptomatic COVID-19, with long COVID symptoms developing a short time later. The two subjects in the long-term control group positive for EBV reactivation were positive for EBV EA-D IgG only. Complete EBV antibody titer assessments of long-term study subjects appear in Appendix A (Tables A1 and A2).

\subsection{Analysis of Secondary (Short-Term) Study Participants}

As those subjects enrolled as participants in the primary study were at least 90 days post-diagnosis of COVID-19, we also examined a secondary population who were between 21 to 90 days (short-term) post-diagnosis of COVID-19. We observed a similar level of EBV reactivation among these short-term subjects. We found that $66.7 \%(6 / 9)$ of short-term long COVID subjects showed evidence of EBV reactivation based on positive titers for EBV EA-D IgG or EBV VCA IgM. Among the short-term control subjects, 11.1\% (1/9) tested positive for EBV reactivation based on positive titers for EBV EA-D IgG or EBV VCA IgM. The difference in the fraction showing evidence of reactivation between the 
short-term long COVID and control subjects was significant ( $p=0.05$, Fisher's exact test). Six short-term long COVID subjects tested positive for EBV EA-D IgG, one of whom also tested positive for EBV VCA IgM. The single subject in the short-term control group indicating EBV reactivation was positive only for EBV EA-D IgG. Complete EBV antibody titer assessments of short-term study subjects appear in Appendix A (Tables A3 and A4).

\subsection{Assessment of EBV EA-D IgG, EBV VCA IgG, and EBNA-1 IgG Titers in All Subjects}

We did three analyses comparing EBV EA-D IgG, EBV VCA IgG, and EBNA-1 IgG antibody titer values against the number of long COVID symptoms reported by each of the 68 subjects making up our primary and secondary study groups to see if any significant relationships were observed. Only EBV EA-D IgG (Figure 1) demonstrated a significant relationship with the number of reported long COVID symptoms $(\mathrm{r}=0.34, p<0.001)$. Neither EBV VCA IgG (Figure A1) nor EBNA-1 IgG (Figure A2), shown in Appendix A, showed a statistically significant relationship with the number of long COVID symptoms.

\section{Long COVID Symptoms vs. EBV EA-D IgG}

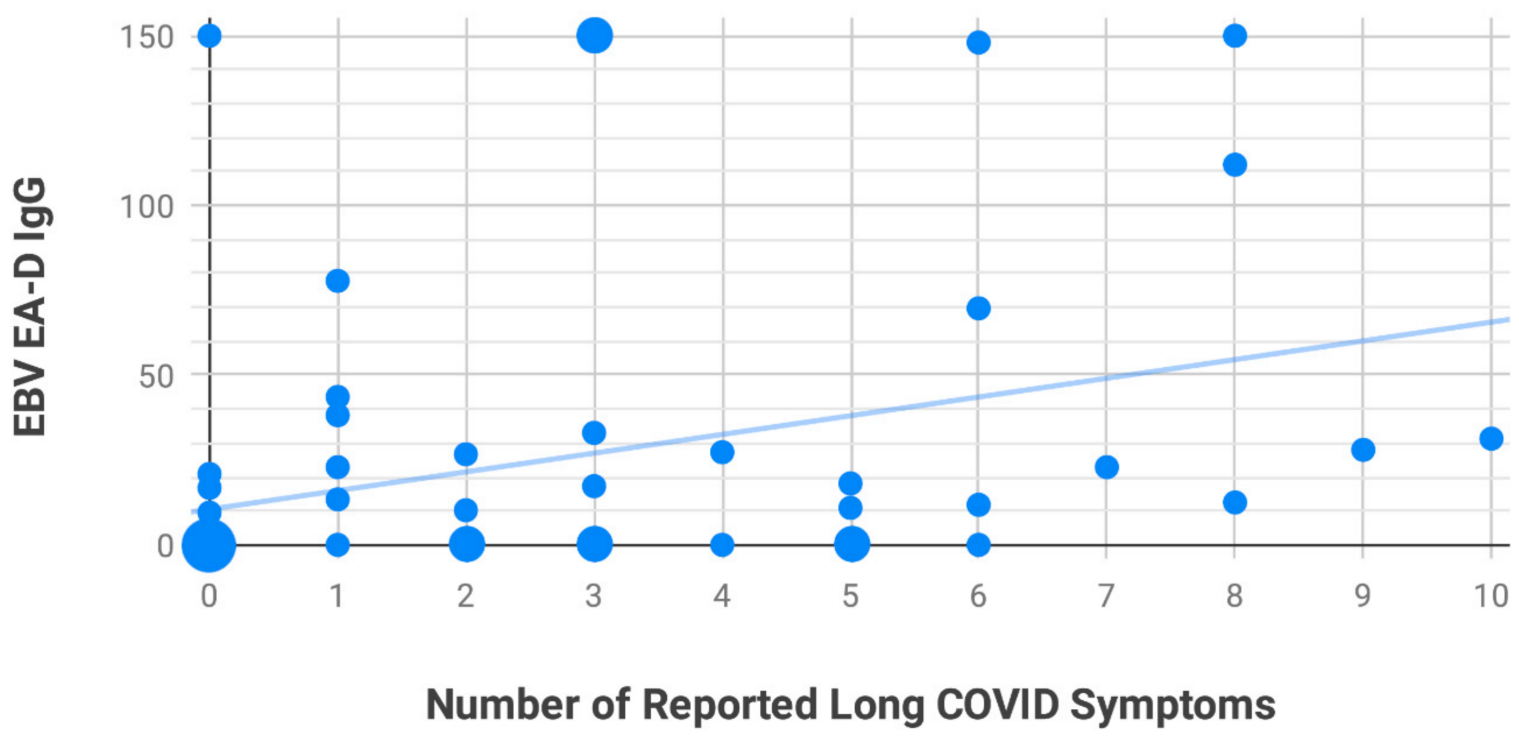

Figure 1. The relationship between EBV early antigen-diffuse (EA-D) IgG antibody titers and reported long COVID symptoms in the 68 subjects making up the primary and secondary groups was significant $(\mathrm{r}=0.34, p<0.001)$.

\subsection{Most Frequently Reported Symptoms}

The most frequently reported symptoms among those who were positive for EBV reactivation from both our long-term and short-term long COVID groups were fatigue, insomnia, headaches, myalgia, and confusion (Figure 2). Seven subjects in the long-term long COVID group experienced tinnitus and/or some hearing loss. Seven subjects in the long-term long COVID group and two subjects in the short-term long COVID group with EBV reactivation experienced frequent skin rashes (Figure 3), including two with COVID toes (Figure 4), a condition associated with some COVID-19 cases [15]. No formal statistical assessment of the frequency of these long COVID manifestations was attempted; our findings were observational only. 


\section{Long COVID Symptoms Prevalence}

Epstein-Barr Virus Reactivation Confirmed $(n=29)$

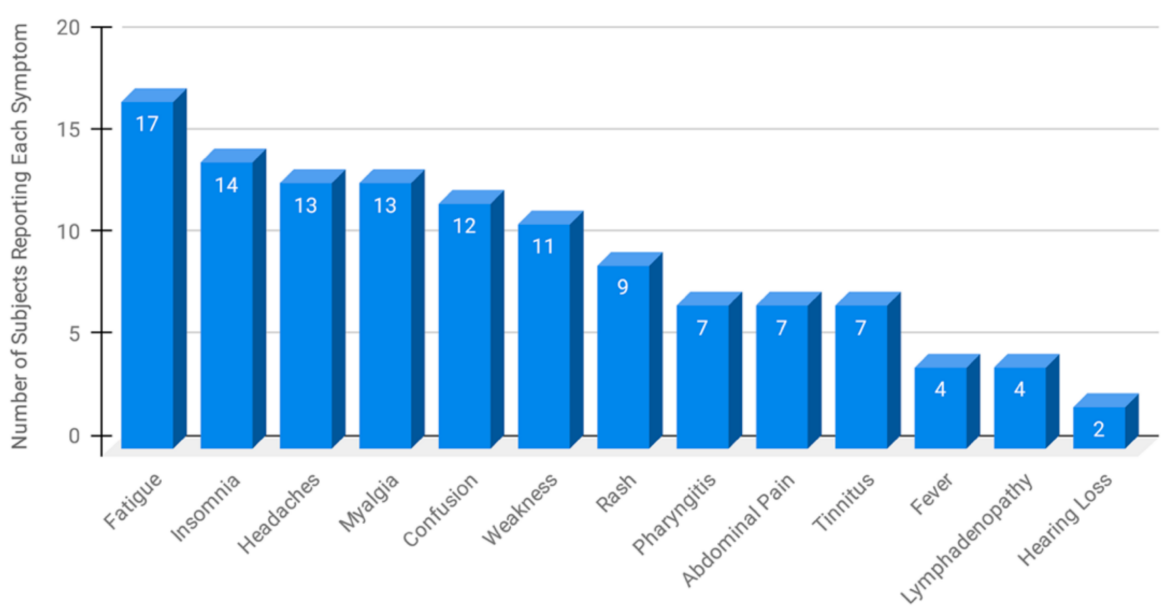

Figure 2. The number of subjects reporting each of 13 clinical manifestations of long COVID, as reported by the 29 subjects from both our long-term and short-term long COVID groups who tested positive for Epstein-Barr virus (EBV) reactivation. The percent of subjects with EBV reactivation reporting each symptom was: fatigue $58.6 \%$, insomnia $48.3 \%$, headaches $44.8 \%$, myalgia $44.8 \%$, confusion/brain fog $41.4 \%$, weakness $37.9 \%$, rash $31.0 \%$, pharyngitis $24.1 \%$, abdominal pain $24.1 \%$, tinnitus $24.1 \%$, fever over $101^{\circ} \mathrm{F} 13.8 \%$, neck lymphadenopathy $13.8 \%$, and mild-to-moderate hearing loss $6.9 \%$.

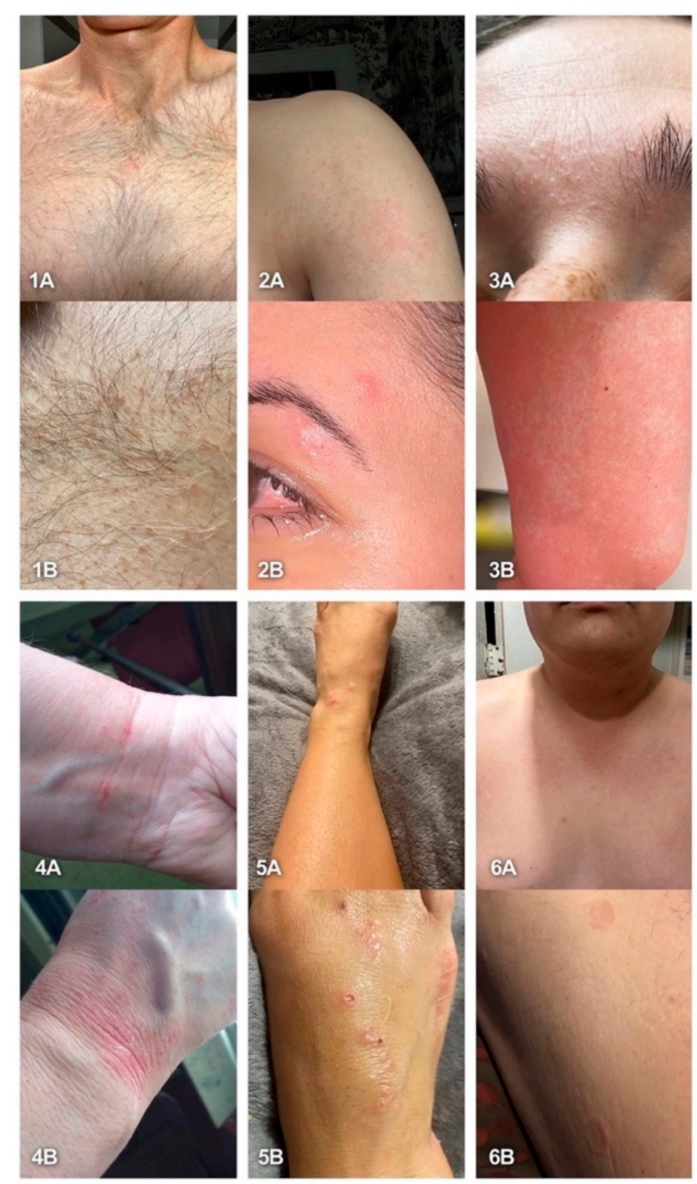

Figure 3. Skin manifestations of six long COVID subjects positive for EBV reactivation (two photos of each subject). 


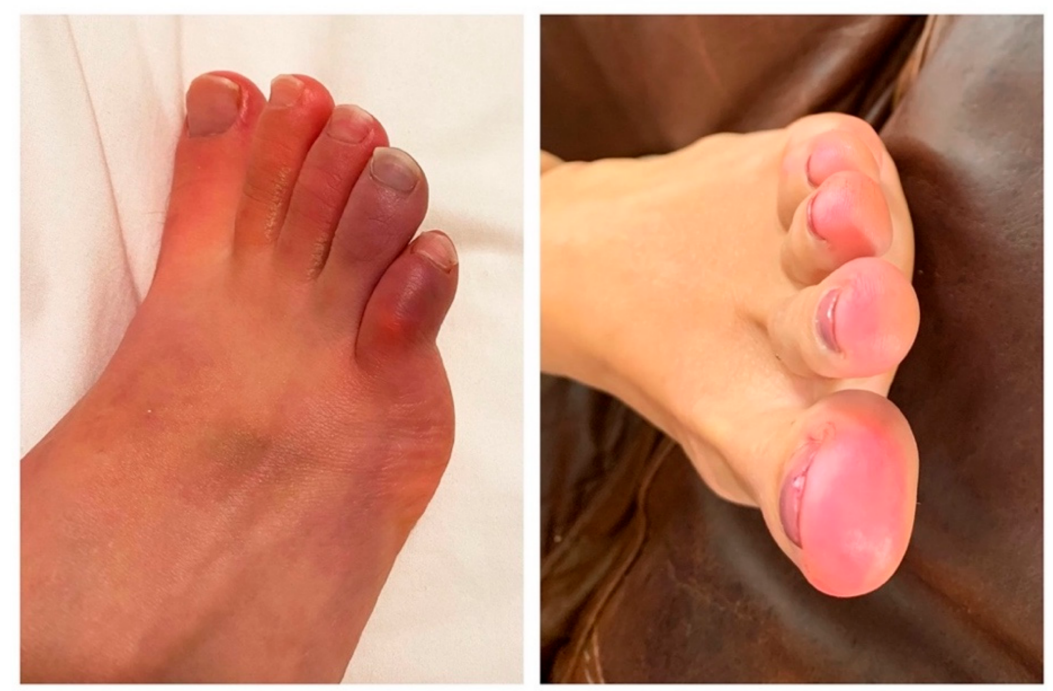

Figure 4. One subject experienced COVID toes at four months and another at nine months after testing positive for Coronavirus disease 2019 (COVID-19).

\section{Discussion}

EBV can be serially reactivated as the result of a variety of stressor events [16]. Stress levels have been linked to the duration and intensity of reactivated EBV infections and variations of the steady-state expression of latent EBV $[17,18]$.

Chen et al. (2021) of Remnin Hospital at Wuhan University in Wuhan, Hubei province, China were the first to document finding EBV reactivation in COVID-19 patients during the acute phase. They found that $55.2 \%$ of hospitalized COVID-19 patients between 9 January 2020 and 29 February 2020 with serological confirmation of past EBV infection also tested positive for EBV VCA IgM, indicating EBV reactivation within two weeks of testing positive for SARS-CoV-2 [19].

Paolucci et al. (2020) tested 104 COVID-19 patients, 42 in an intensive care unit (ICU) and 62 in a sub-intensive care unit (SICU) in Italy and observed EBV reactivation in $95.2 \%(40 / 42)$ of the ICU patients and in $83.6 \%(51 / 61)$ of the SICU patients. They further determined that the median EBV DNA level in ICU patients was significantly higher than that of SICU patients [20]. A similar study in France found evidence of EBV reactivation in $82 \%(28 / 34)$ of COVID-19 ICU patients. Further, they found EBV reactivation to be associated with longer median ICU stays (15 days versus 8 days, $p<0.05$ ) [21].

Lehner et al. (2020) ran EBV and cytomegalovirus (CMV) DNA tests on COVID19 patients in the Medical ICU at the Medical University Innsbruck, Austria and found that $78 \%$ of the COVID-19 patients they tested with respiratory failure requiring invasive ventilation had evidence of EBV viremia [22]. However, CMV viremia was not found to be any more common in COVID-19 patients than in non-COVID-19 patients.

While a limitation of our study is that we were not able to pinpoint the exact timing of EBV reactivation in the subjects we studied, given that we found similar reactivation frequencies in both long-term and short-term long COVID subjects, this indicates a likelihood that EBV reactivation occurs early in SARS-CoV-2 infection. Early EBV reactivation has been previously documented in several studies of COVID-19 ICU patients [20-23].

More than $90 \%$ of adults carry antibodies indicating past EBV infection. These infections most often occur from childhood through the early twenties. When primary infection occurs in the teens or later, infectious mononucleosis can be the clinical result. In the United States, there is a recognized racial disparity in the typical age of primary EBV infection. Seroprevalence of prior EBV infection in those under age 20 is much higher among Hispanic Americans (85.4\%, 95\% CI 83.1-87.8\%) and Non-Hispanic Blacks (83.1\%, 95\% CI 81.1-85.1\%) than in Non-Hispanic Whites (56.9\%, 95\% CI 54.1-59.8\%). The greatest disparity is observed through age 14 [24]. 
Two tests used to detect prior EBV infection in clinical practice, EBV VCA IgG and EBV nuclear antigen 1 (EBNA-1) IgG, return a positive result soon after primary EBV infection and typically remain positive for life. A positive result for both is typically indicative of past EBV infection. A positive result for EBV VCA IgG, but not for EBNA-1 IgG, may also indicate a past EBV infection in cases where patients were immunosuppressed or when individuals never produced EBNA-1 IgG at all [25].

EBV reactivation is typically identified by testing for the presence of EBV EA-D IgG or EBV VCA IgM [11-13]. EBV reactivation can also identified by testing for the presence of circulating EBV DNA utilizing a serum EBV DNA quantitative real-time polymerase chain reaction (PCR) test. EBV EA-D IgG, EBV VCA IgM, and serum EBV DNA are often detectable at separate times during the course of primary or reactivated EBV infection (Figure 5), requiring the use of multiple testing methods to accurately determine if an individual is positive for EBV reactivation. While EBV DNA is most often detectable during the acute early stage of primary or reactivated EBV infection, EBV DNA can also be detected at other stages of EBV infection, depending on the sensitivity of the quantitative PCR tests used [26,27], as well as the frequency of testing.

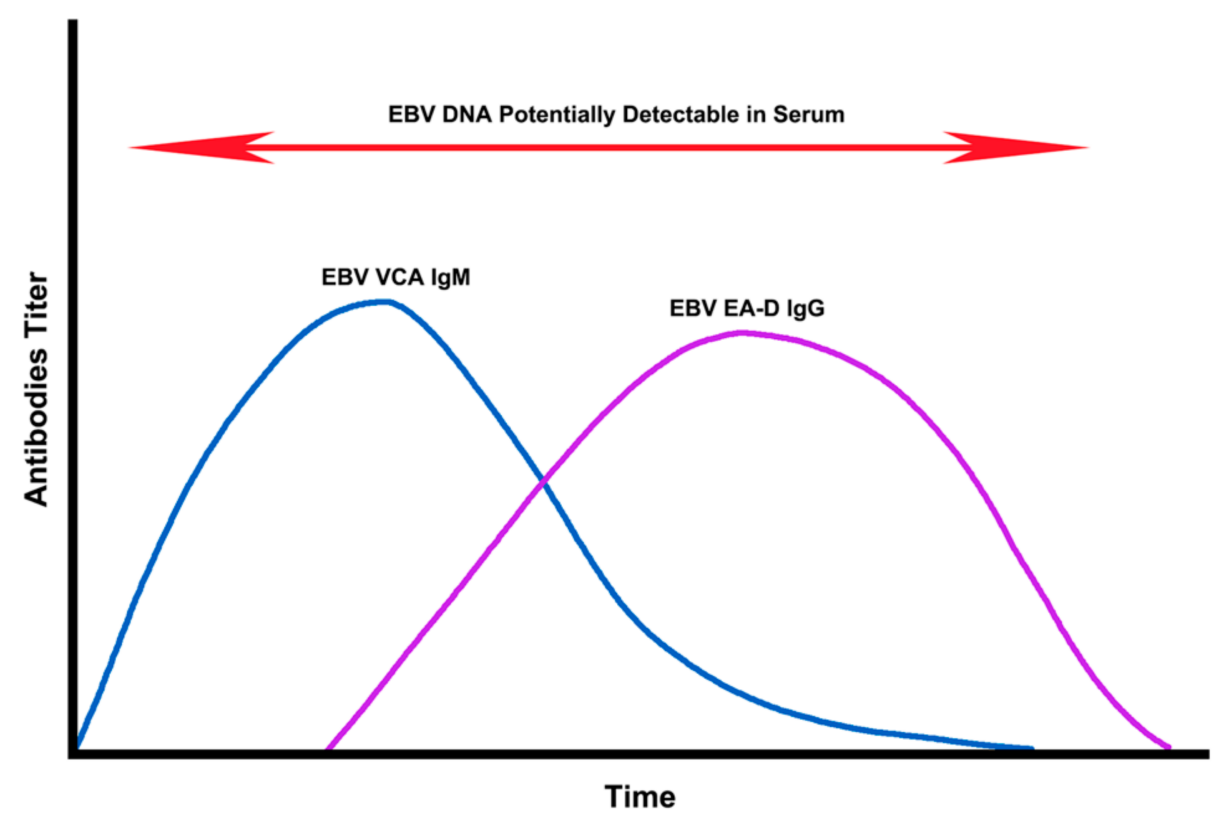

Figure 5. The dynamics of EBV viral capsid antigen (VCA) IgM titers, EBV early antigen-diffuse (EA-D) IgG titers, and serum EBV DNA over time after EBV infection or reactivation [14,26-28].

In order to investigate how serum EBV DNA tests may help clinicians further identify patients with EBV reactivation, we utilized a commercial EBV DNA quantitative real-time PCR test on all long-term and short-term long COVID subjects who tested negative for both EBV EA-D IgG and EBV VCA IgM. EBV DNA testing identified two additional subjects in the long-term long COVID group showing evidence of EBV reactivation based on the presence of circulating EBV DNA (465 copies/mL and 481 copies/mL) and one additional short-term long COVID subject positive for EBV reactivation based on the presence of circulating EBV DNA (578 copies/mL). The commercial assay source we used indicated that a minimum of 200 copies $/ \mathrm{mL}$ constituted a positive test. Once those positive for EBV DNA were added to the dataset of subjects already found to be positive for EBV reactivation, we found that $73.3 \%$ (22/30) of long-term long COVID subjects and $77.8 \%$ (7/9) of short-term long COVID subjects showed evidence of EBV reactivation.

EBV reactivation is known to induce a diverse set of rashes and skin lesions that include urticaria [29], granuloma annulare [30], folliculitis [31], cryoglobulinemia [32,33], and Raynaud's phenomenon [34], which resembles COVID toes [35]. One of the earliest documented cases of COVID toes was described in Madrid, Spain by Nirenberg et al. in 
April 2020 in a 16-year-old female who had a coinfection of EBV and COVID-19 [36]. A wide variety of skin manifestations were reported by nine subjects among our study groups who tested positive for EBV reactivation, including two who experienced COVID toes: one at four months and the other at nine months post-diagnosis of COVID-19.

EBV has been associated with tinnitus and hearing loss [37,38]. Tinnitus is a common long COVID symptom and was reported by seven subjects in our study groups who tested positive for EBV reactivation. Mild-to-moderate hearing loss was reported by two subjects in our study groups who tested positive for EBV reactivation. Unexplained hearing loss and tinnitus tied to SARS-CoV-2 have been documented in various case reports and small studies [39-41].

In addition to the more common manifestations described earlier, EBV reactivation has also been associated with cardiovascular, hematological, and neurological complications [42]. EBV reactivation has been reported to play a role in the pathogenesis of myocarditis [43], inflammatory cardiomyopathy [44], and acute myocardial infarction [45]. EBV-associated multisystem failure has been documented to also result in acute liver injury, kidney injury, respiratory failure, and hemolytic anemia in immunocompetent patients [46]. EBV is also associated with a number of lymphoid and epithelial tumors [47]. While rare, given that EBV reactivation has been associated with many serious clinical manifestations, further study would be prudent to determine if any of these become more frequent in COVID-19 patients.

Currently, there are no pharmaceuticals licensed to specifically treat EBV reactivation. Some anti-DNA viral agents have been used to attempt to reduce the viral load in reactivation of herpes viruses. Some level of efficacy in the management of EBV disease has been demonstrated when using these drugs. Extended administration of valacyclovir is known to reduce the frequency of EBV-infected B cells and has been theorized as a treatment to eradicate EBV from the body [48]. Spironolactone has been found in vitro to inhibit EBV VCA synthesis and capsid formation [49]. Spironolactone is also being studied as a potential therapeutic for SARS-CoV-2 infection itself [50,51]. Further evidence that EBV may be contributing to COVID-19 disease comes from a clinical study in Wuhan. This study showed that treatment with ganciclovir, an anti-herpesvirus drug that blocks the replication of EBV, reduced the risk of death in patients with severe disease [52].

An awareness of the associations between SARS-CoV-2 and EBV reactivation creates new opportunities for long COVID diagnosis, management, and possible treatments. We believe that it would be prudent to determine if patients who have tested positive for COVID-19 have evidence of EBV reactivation, whether showing classical acute disease or not. If they do show signs of EBV reactivation, then it would be clinically appropriate to monitor for the development of known EBV disease manifestations, particularly those that are shared with the long COVID complex.

Our study opens up several new avenues for future research. Long COVID patients' antibody responses to CMV could be studied alongside EBV to determine whether CMV may also be reactivated in some cases of long COVID. Given the numerous skin manifestations observed in long COVID cases, it would be interesting to investigate if EBV viral loads can be observed in enriched T cells in such cases. Another area for study would be to test peripheral blood mononuclear cells (PBMCs) of long COVID patients to determine if the cellular immune compartment or serum factors facilitate EBV reactivation.

In conclusion, our results indicate that approximately 30\% of COVID-19 patients report long COVID-like symptoms after acute disease. EBV reactivation may occur soon after or concomitantly with COVID-19 infection, including after initially asymptomatic infections. The SARS-CoV-2 virus may stimulate sequalae involving other infectious agents that contribute to many long COVID symptoms. Thus, it is worth considering that a portion of long COVID symptoms may be the result of COVID-19 inflammation-induced EBV reactivation. 


\section{Materials and Methods}

\subsection{Study Design}

We screened 357 applicants (Figure 6) using a Health Insurance Portability and Accountability Act (HIPAA)-compliant online form under which informed consent was obtained. As an assurance of confidentiality, only one investigator performed recruitment, data collection, and validation. Patient data was kept in a secure database that was used only in coded form (to remove all patient identifiers) before the analysis of the data by the research team. Thus, all patient records, test data, and the identity of the subjects submitting photos of skin manifestations were kept by a single source.

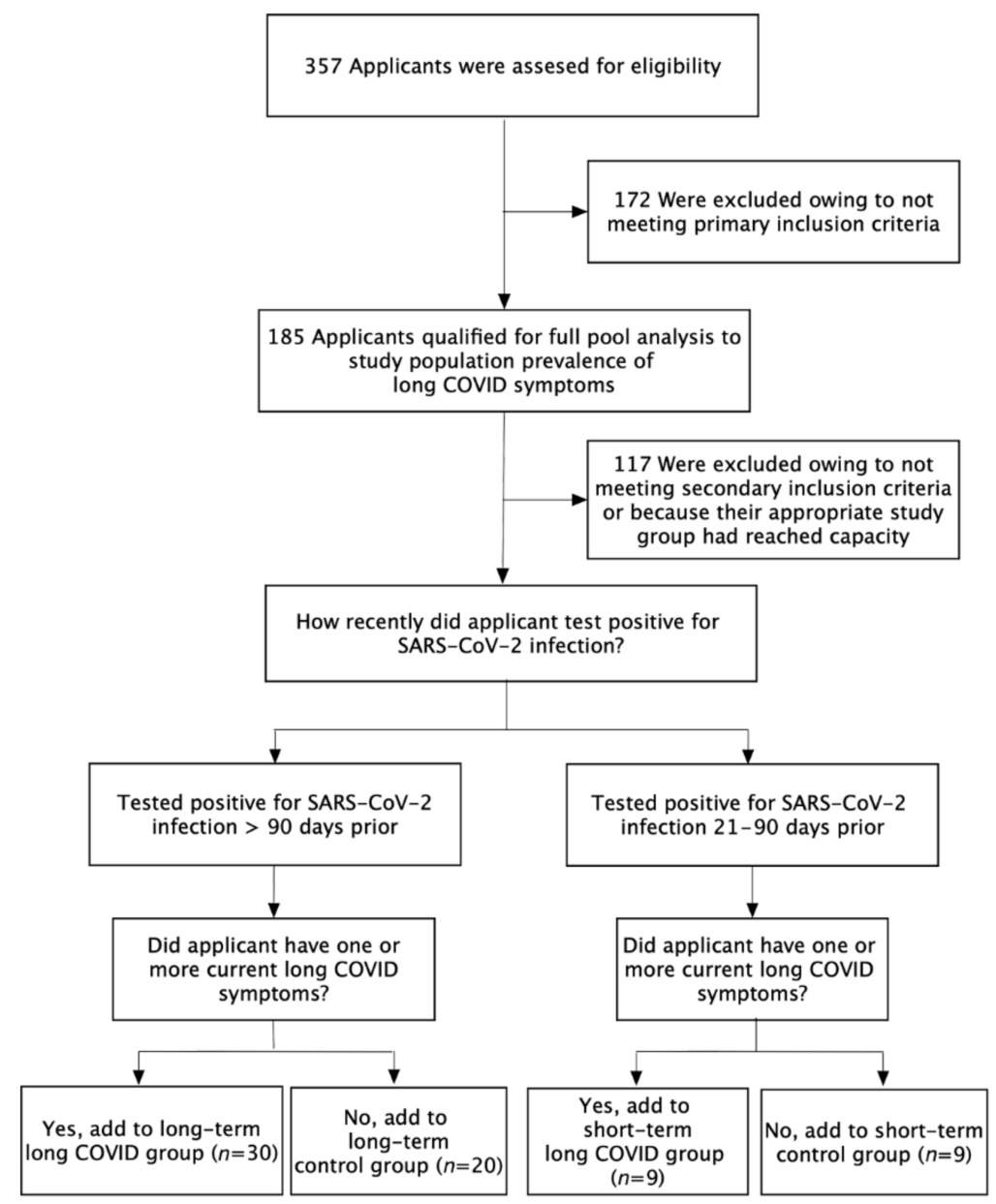

Figure 6. Primary inclusion: subjects were included only if they provided the requested background, including documentation of their COVID-19 diagnosis, most often in the form of SARS-CoV-2 polymerase chain reaction (PCR) results. Secondary inclusion: subjects were included only if between the ages of 21-74, with no exclusionary health conditions.

\subsection{Patient Recruitment}

Subjects were chosen from applicants who responded to online advertisements seeking recovered COVID-19 patients for this study. Potential subjects were only aware that we wished to collect data related to their experience with COVID-19 disease, thus limiting selfselection bias. Each applicant was required to upload documentation of their COVID-19 medical history. This included copies of COVID-19 test results and hospitalization records, as well as completing an in-depth online survey in which they provided details related to their COVID-19 symptoms and outcomes on the HIPAA-compliant form. Follow-up was done by one investigator to verify that each subject met the study criteria and to allow subjects demonstrating skin manifestations to provide images of such for the record and to be kept in blinded files for evaluation by the remaining researchers. Subjects in the 
study were selected randomly from all who applied and were a match to the criteria for any of the study groups. Applicants were excluded if under 21 years of age, over 74 years of age, if they were pregnant, had been given a COVID-19 vaccine, or had symptoms similar to long COVID prior to testing positive for COVID-19. The selection process continued until 68 qualified subjects were added to the study pool. These subjects provided serological samples at a clinical laboratory to be tested for the relevant EBV parameters. The selection of applicants and serological testing was conducted from 11 December 2020 through 11 February 2021. A small stipend to help defray costs associated with providing records and blood samples was available to subjects.

\subsection{Primary and Secondary Study Groups}

We divided subjects into four groups: two primary (long-term) study groups and two secondary (short-term) study groups. The "long-term long COVID group" consisted of 30 subjects; all had tested positive for COVID-19 at least 90 days prior to being enrolled, and all reported one or more of the long COVID symptoms utilized for this study. The "long-term control group" consisted of 20 subjects; all had tested positive for COVID-19 at least 90 days prior to enrollment, and none reported any of the long COVID symptoms we were assessing. The "short-term long COVID group" consisted of 9 subjects; all had tested positive for COVID-19 21-90 days prior to enrollment, and all reported one or more of the long COVID symptoms utilized for this study. The "short-term control group" consisted of 9 subjects; all had tested positive for COVID-19 21-90 days prior to enrollment, and none reported any of the long COVID symptoms we were assessing.

Long COVID subjects were those that reported one or more of the following unabating symptoms after recovering from initial SARS-CoV-2 infection: fatigue, insomnia, headaches, myalgia, confusion/brain fog, weakness, rash, pharyngitis, abdominal pain, tinnitus, fever over $101^{\circ} \mathrm{F}$, neck lymphadenopathy, or mild-to-moderate hearing loss.

The age and the sex of long-term long COVID subjects versus long-term control subjects (Table 1) were commensurate with each other. Additionally, the geographic distribution of participants across United States census regions (Table 2) gave us no reason to conclude that the distribution was unequal. Therefore, we believe there was little chance significant bias was introduced by the selection process for study applicants.

Table 1. Characteristics of participants in the primary (long-term) study groups (plus-minus values are means $\pm \mathrm{SD})$.

\begin{tabular}{ccc}
\hline Characteristic & $\begin{array}{c}\text { Long-Term } \\
\text { Long COVID Group }\end{array}$ & $\begin{array}{c}\text { Long-Term } \\
\text { Control Group }\end{array}$ \\
\hline Mean Age & $43.8 \pm 13.4$ & $43.9 \pm 13.7$ \\
\hline$\leq 40$ years-no. $(\%)$ & $14(46.7)$ & $9(45.0)$ \\
\hline$>40$ years-no. $(\%)$ & $16(53.3)$ & $11(55.0)$ \\
\hline Female-no. $(\%)$ & $23(76.7)$ & $14(70.0)$ \\
\hline Male-no. $(\%)$ & $7(23.3)$ & $6(30.0)$ \\
\hline
\end{tabular}

Table 2. Geographic distribution of participants in the primary (long-term) study groups ${ }^{1}$.

\begin{tabular}{ccc}
\hline $\begin{array}{c}\text { United States } \\
\text { Census Region }\end{array}$ & $\begin{array}{c}\text { Long-Term } \\
\text { Long COVID Group }\end{array}$ & $\begin{array}{c}\text { Long-Term } \\
\text { Control Group }\end{array}$ \\
\hline Region 1: Northeast-no. & 10 & 4 \\
\hline Region 2: Midwest-no. & 5 & 3 \\
\hline Region 3: South-no. & 5 & 6 \\
\hline Region 4: West-no. & 10 & 7 \\
\hline
\end{tabular}

${ }^{1}$ We tested the null hypothesis that the distribution of subjects in each of the groups was not different using Fisher's exact test $(p=0.65)$. 


\subsection{Assessments}

All study participants volunteered to provide blood samples through a clinical reference laboratory (Quest Diagnostics, Secaucus, NJ, USA). The samples were tested for EBV VCA IgM, EBV VCA IgG, EBNA-1 IgG, and EBV EA-D IgG, as shown in Appendix A (Tables A1-A4). Subjects with long COVID symptoms who did not test positive for EBV VCA IgM or EBV EA-D IgG were also tested for EBV DNA with a quantitative real-time PCR test with a linear range of 200-2,000,000 copies/mL.

EBV antibodies were measured using a LIAISON®Analyzer (DiaSorin, Centralino, Italy) to measure the chemiluminescence from a commercially available immunoassay (CLIA) for the qualitative determination of IgG and IgM antibodies in human serum specimens. The method for qualitative determination of specific $\operatorname{IgG}$ and $\operatorname{IgM}$ antibodies to EBV was a competitive (indirect) CLIA. The principal components of the EBV VCA IgG and EBV VCA IgM tests were magnetic particles coated with VCA p18 synthetic peptide, BSA, and a phosphate buffer containing $<0.1 \%$ sodium azide. The principal components of the EBNA-1 IgG tests were magnetic particles coated with EBNA-1 synthetic peptide, BSA, and a phosphate buffer containing $<0.1 \%$ sodium azide. The principal components of the EBV EA-D IgG tests were magnetic particles coated with EA-D polypeptide (obtained in E. coli by recombinant DNA technology), BSA, and a phosphate buffer containing $<0.1 \%$ sodium azide. The EBV DNA quantitative real-time PCR test was developed in-house, and its analytical performance was validated by Quest Diagnostics.

When EBV VCA IgM can be detected but EBNA-1 IgG cannot, this generally indicates primary EBV infection or EBV reactivation. When EBV VCA IgM and EBNA-1 IgG are both detectable, this generally indicates EBV reactivation. EBV EA-D IgG is generally only detected in patients with either primary infection or EBV reactivation. Thus, testing for the presence of EBV VCA IgM or EBV EA-D IgG has been commonly used to detect EBV reactivation [11-13]. Some reactivation cases missed by titer tests can be detected through serum testing for the presence of EBV DNA circulating following viral release during recrudescence. In our study, a subject was classified as having EBV reactivation if they exceeded any of these threshold values: EBV VCA IgM $>39.99 \mathrm{U} / \mathrm{mL}$, EBV EA-D IgG $>9.99 \mathrm{U} / \mathrm{mL}$, or EBV DNA quantitative, real-time PCR > 199 copies $/ \mathrm{mL}$.

\subsection{Review of Photographs}

Subjects with skin manifestations of long COVID provided photographs of their own skin problems. The investigators participating in this study reviewed the blinded images of skin manifestations provided by the collecting investigator to determine if they were consistent with skin manifestations that were reported in other long COVID patients and people with recurring EBV reactivation. A consensus was found that the images presented here represented lesions described for both conditions. No formal statistical assessment of these manifestations was attempted, and the data was provided descriptively.

\subsection{Statistical Analysis}

We used Fisher's exact test to compare reactivation rates in the long COVID groups versus the control groups. All calculations of statistical significance and power analysis related to sample size were performed using $\mathrm{R}$ (The R Foundation for Statistical Computing, version 4.0.3, Vienna, Austria). A value of $p \leq 0.05$ was considered to indicate statistical significance. We planned for a sample size of 30 in the long-term long COVID group and a sample size of 20 in the long-term control group, yielding $99 \%$ power using an expected difference of $80 \%$ versus $20 \%$, respectively. (Assumptions: two-sided Z-test applied to the arcsine transformation of the proportions, alpha $=0.05$.) All power analyses (for sample size) and calculations of statistical significance were completed independently by statisticians Nayak Polissar, PhD and Ljubomir Miljacic, PhD, MS (Seattle, WA, USA). 
Author Contributions: Conceptualization, J.E.G.; methodology, J.E.G. and D.J.H.; validation, J.E.G., R.A.O., W.E.L. and D.J.H.; formal analysis, J.E.G. and D.J.H.; investigation, J.E.G. and D.J.H.; resources, J.E.G.; data curation, J.E.G. and D.J.H.; writing —original draft preparation, J.E.G. and D.J.H.; writingreview and editing, J.E.G., R.A.O., W.E.L. and D.J.H.; visualization, J.E.G.; supervision, D.J.H.; and project administration, J.E.G. All authors have read and agreed to the published version of the manuscript.

Funding: This research received no external funding.

Institutional Review Board Statement: The study was conducted according to the guidelines of the Declaration of Helsinki and approved by the Institutional Review Board of Integrity IRB (Protocol number 40005; Date of approval: 9 December 2020).

Informed Consent Statement: Informed consent was obtained from all subjects in the study.

Data Availability Statement: A complete database of deidentified individual subject data for all measured parameters is available online at Dryad: https://doi.org/10.5061/dryad.c866t1g67.

Acknowledgments: We thank all study subjects and gratefully acknowledge the following contributors to this work, who did not receive any specific compensation for their contributions: Lawrence S. Young for helpful review of the manuscript, Matthew S. Carducci and Joy B. Chastain for their helpful discussions, and John M. Keating for the editing assistance.

Conflicts of Interest: The authors declare no conflict of interest.

\section{Appendix A Epstein-Barr Virus Antibody Panel Results}

Table A1. Long-Term long COVID group Epstein-Barr virus antibody panel results (- = negative).

\begin{tabular}{|c|c|c|c|c|}
\hline ID & EBV EA-D IgG & EBV VCA IgM & EBV VCA IgG & EBNA-1 IgG \\
\hline 06966 & - & 81.4 & $>750$ & $>600$ \\
\hline 13444 & 148 & - & 143 & 460 \\
\hline 13459 & - & - & 202 & 143 \\
\hline 15170 & - & - & $>750$ & 532 \\
\hline 15366 & 10.2 & - & 401 & 576 \\
\hline 15994 & - & - & $>750$ & 548 \\
\hline 16370 & 69.7 & - & $>750$ & - \\
\hline 16381 & - & - & 153 & 74.4 \\
\hline 16968 & 22.9 & - & $>750$ & $>600$ \\
\hline 16979 & $>150$ & - & $>750$ & 273 \\
\hline 17050 & - & - & $>750$ & 351 \\
\hline 17113 & 77.8 & 69.1 & 106 & 490 \\
\hline 17332 & 13.4 & - & 87.2 & 97.8 \\
\hline 17706 & - & - & 31.1 & 378 \\
\hline 35143 & 18.1 & - & 81.9 & 582 \\
\hline 35145 & $>150$ & - & 620 & 196 \\
\hline 35188 & 26.7 & - & 602 & 446 \\
\hline 35946 & 112 & - & $>750$ & 384 \\
\hline 83584 & - & 67.1 & 364 & 588 \\
\hline 83821 & $>150$ & - & 153 & 21 \\
\hline 83860 & - & - & $>750$ & $>600$ \\
\hline 83893 & 28 & - & 179 & 207 \\
\hline 83925 & - & - & 95 & 506 \\
\hline 83929 & 10.9 & - & 43.4 & 24.1 \\
\hline
\end{tabular}


Table A1. Cont.

\begin{tabular}{ccccc}
\hline ID & EBV EA-D IgG & EBV VCA IgM & EBV VCA IgG & EBNA-1 IgG \\
\hline 83938 & 31.3 & - & 639 & 126 \\
\hline 87629 & - & - & $>750$ & 251 \\
\hline 87634 & - & - & 74.4 & $>600$ \\
\hline 87987 & 17.3 & - & 289 & 175 \\
\hline 87999 & 33 & - & $>750$ & 474 \\
\hline 94332 & 22.9 & - & 29.1 & 287 \\
\hline
\end{tabular}

Table A2. Long-term control group Epstein-Barr virus antibody panel results (- = negative).

\begin{tabular}{|c|c|c|c|c|}
\hline ID & EBV EA-D IgG & EBV VCA IgM & EBV VCA IgG & EBNA-1 IgG \\
\hline 13481 & - & - & 198 & 372 \\
\hline 16169 & - & - & 134 & 149 \\
\hline 16199 & 16.8 & - & $>750$ & 502 \\
\hline 16710 & - & - & 680 & $>600$ \\
\hline 16715 & - & - & 573 & 187 \\
\hline 16721 & - & - & 125 & $>600$ \\
\hline 16755 & - & - & - & - \\
\hline 16832 & - & - & 198 & 48.7 \\
\hline 17783 & - & - & 91.9 & $>600$ \\
\hline 17804 & - & - & 302 & $>600$ \\
\hline 83740 & - & - & $>750$ & 460 \\
\hline 83859 & - & - & 53 & 559 \\
\hline 83911 & - & - & $>750$ & 400 \\
\hline 83924 & - & - & 74.6 & 132 \\
\hline 83966 & - & - & $>750$ & 589 \\
\hline 84549 & - & - & 129 & 434 \\
\hline 85068 & 9.51 & - & $>750$ & $>600$ \\
\hline 87612 & - & - & $>750$ & 96.6 \\
\hline 87994 & $>150$ & - & $>750$ & $>600$ \\
\hline 93070 & - & - & $>750$ & 238 \\
\hline
\end{tabular}

Table A3. Short-term long COVID group Epstein-Barr virus antibody panel results (- = negative).

\begin{tabular}{ccccc}
\hline ID & EBV EA-D IgG & EBV VCA IgM & EBV VCA IgG & EBNA-1 IgG \\
\hline 13963 & - & - & $>750$ & 421 \\
\hline 16378 & 43.6 & - & 92.3 & 536 \\
\hline 16555 & - & - & 271 & 26.2 \\
\hline 16717 & 38.2 & - & 392 & - \\
\hline 16750 & 27.3 & - & 418 & - \\
\hline 17106 & - & - & $>750$ & $>600$ \\
\hline 17323 & $>150$ & - & 186 & 170 \\
\hline 17387 & 12.5 & 47.5 & $>750$ & 43.7 \\
\hline 17390 & 11.8 & - & 140 & 395 \\
\hline
\end{tabular}


Table A4. Short-term control group Epstein-Barr virus antibody panel results (- = negative).

\begin{tabular}{ccccc}
\hline ID & EBV EA-D IgG & EBV VCA IgM & EBV VCA IgG & EBNA-1 IgG \\
\hline 07506 & - & - & 221 & 214 \\
\hline 09092 & - & - & $>750$ & 549 \\
\hline 15509 & 20.9 & - & 372 & $>600$ \\
\hline 16406 & - & - & $>750$ & - \\
\hline 16642 & - & - & 590 & 218 \\
\hline 16770 & - & - & 256 & $>600$ \\
\hline 92742 & - & - & $>750$ & - \\
\hline 93074 & - & - & 527 & $>600$ \\
\hline 94266 & - & - & $>750$ & - \\
\hline
\end{tabular}

\section{Long COVID Symptoms vs. EBV VCA IgG}

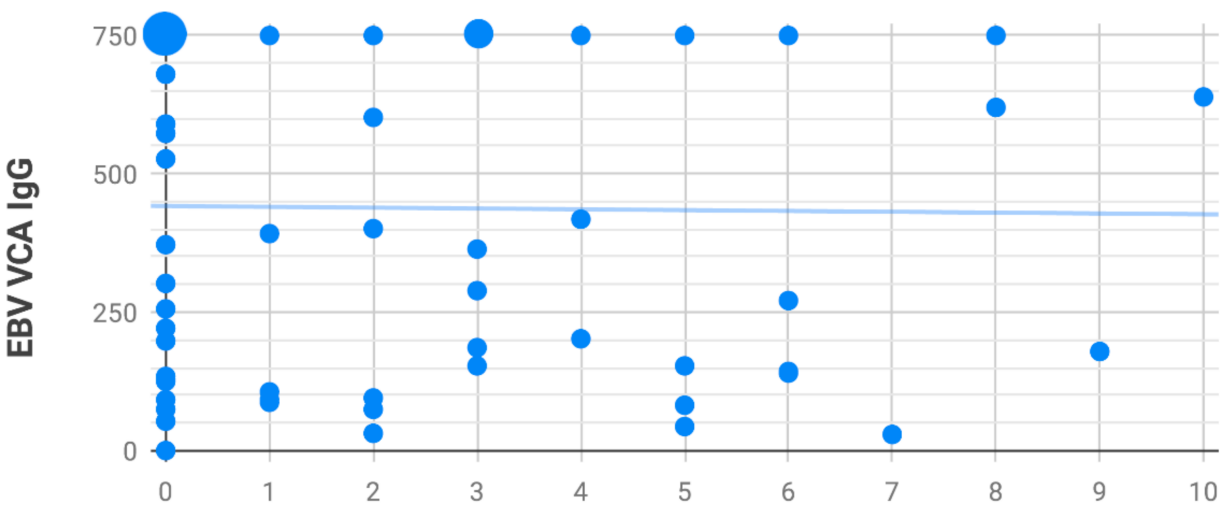

Number of Reported Long COVID Symptoms

Figure A1. The relationship between EBV VCA IgG antibody titers and reported long COVID symptoms in the 68 subjects making up the primary and secondary groups was not significant $(\mathrm{r}=-0.014, p=0.75)$.

\section{Long COVID Symptoms vs. EBNA-1 IgG}

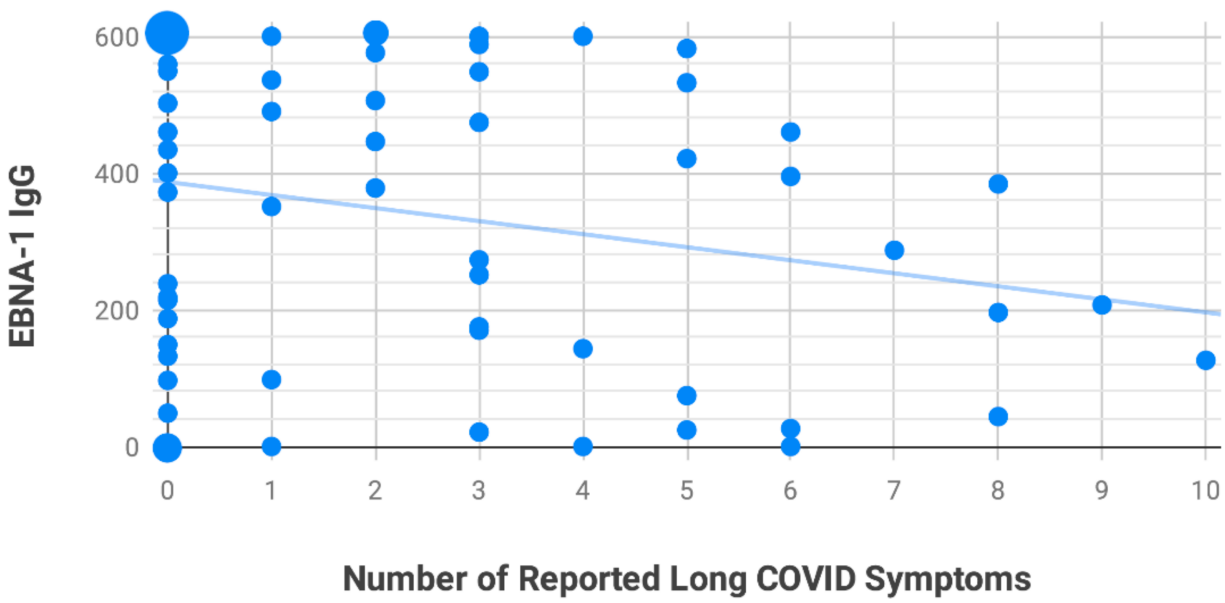

Figure A2. The relationship between EBV nuclear antigen 1 (EBNA-1) IgG antibody titers and reported long COVID symptoms in the 68 subjects making up the primary and secondary groups was not significant $(\mathrm{r}=-0.23, p=0.09)$. 


\section{References}

1. Logue, J.K.; Franko, N.M.; McCulloch, D.J.; McDonald, D.; Magedson, A.; Wolf, C.R.; Chu, H.Y. Sequelae in Adults at 6 Months After COVID-19 Infection. JAMA Netw. Open 2021, 4, e210830. [CrossRef] [PubMed]

2. Greenhalgh, T.; Knight, M.; A'Court, C.; Buxton, M.; Husain, L. Management of post-acute covid-19 in primary care. BMJ 2020, 370, m3026. [CrossRef] [PubMed]

3. Al-Jahdhami, I.; Al-Naamani, K.; Al-Mawali, A. The Post-acute COVID-19 Syndrome (Long COVID). Oman Med. J. 2021, 36, e220. [CrossRef] [PubMed]

4. Garrigues, E.; Janvier, P.; Kherabi, Y.; Le Bot, A.; Hamon, A.; Gouze, H.; Doucet, L.; Berkani, S.; Oliosi, E.; Mallart, E.; et al. Post-discharge persistent symptoms and health-related quality of life after hospitalization for COVID-19. J. Infect. 2020, 81, e4-e6. [CrossRef] [PubMed]

5. Huang, C.; Huang, L.; Wang, Y.; Li, X.; Ren, L.; Gu, X.; Kang, L.; Guo, L.; Liu, M.; Zhou, X.; et al. 6-month consequences of COVID-19 in patients discharged from hospital: A cohort study. Lancet 2021, 397, 220-232. [CrossRef]

6. Callard, F.; Perego, E. How and why patients made Long Covid. Soc. Sci. Med. 2021, 268, 113426. [CrossRef]

7. Neves, M.; Marinho-Dias, J.; Ribeiro, J.; Sousa, H. Epstein-Barr virus strains and variations: Geographic or disease-specific variants? J. Med. Virol. 2017, 89, 373-387. [CrossRef]

8. Kanda, T.; Yajima, M.; Ikuta, K. Epstein-Barr virus strain variation and cancer. Cancer Sci. 2019, 110, 1132-1139. [CrossRef]

9. Misko, I.S.; Cross, S.M.; Khanna, R.; Elliott, S.L.; Schmidt, C.; Pye, S.J.; Silins, S.L. Crossreactive recognition of viral, self, and bacterial peptide ligands by human class I-restricted cytotoxic T lymphocyte clonotypes: Implications for molecular mimicry in autoimmune disease. Proc. Natl. Acad. Sci. USA 1999, 96, 2279-2284. [CrossRef]

10. Houen, G.; Trier, N.H. Epstein-Barr Virus and Systemic Autoimmune Diseases. Front. Immunol. 2020, 11, 587380. [CrossRef]

11. Straus, S.E.; Tosato, G.; Armstrong, G.; Lawley, T.; Preble, O.T.; Henle, W.; Davey, R.; Pearson, G.; Epstein, J.; Brus, I.; et al. Persisting illness and fatigue in adults with evidence of Epstein-Barr virus infection. Ann. Intern. Med. 1985, 102, 7-16. [CrossRef]

12. Stowe, R.P.; Pierson, D.L.; Feeback, D.L.; Barrett, A.D. Stress-induced reactivation of Epstein-Barr virus in astronauts. Neuroimmunomodulation 2000, 8, 51-58. [CrossRef]

13. Schaade, L.; Kleines, M.; Hausler, M. Application of virus-specific immunoglobulin M (IgM), IgG, and IgA antibody detection with a polyantigenic enzyme-linked immunosorbent assay for diagnosis of Epstein-Barr virus infections in childhood. J. Clin. Microbiol. 2001, 39, 3902-3905. [CrossRef]

14. Smatti, M.K.; Al-Sadeq, D.W.; Ali, N.H.; Pintus, G.; Abou-Saleh, H.; Nasrallah, G.K. Epstein-Barr Virus Epidemiology, Serology, and Genetic Variability of LMP-1 Oncogene Among Healthy Population: An Update. Front. Oncol. 2018, 8, 211. [CrossRef]

15. Baeck, M.; Herman, A. COVID toes: Where do we stand with the current evidence? Int. J. Infect. Dis. 2021, 102, 53-55. [CrossRef]

16. Kasl, S.V.; Evans, A.S.; Niederman, J.C. Psychosocial risk factors in the developmental of infectious mononucleosis. Psychosom. Med. 1979, 41, 445-466. [CrossRef]

17. Glaser, R.; Rice, J.; Sheridan, J.; Fertel, R.; Stout, J.; Speicher, C.; Pinsky, D.; Kotur, M.; Post, A.; Beck, M.; et al. Stress-related immune suppression: Health implications. Brain Behav. Immun. 1987, 1, 7-20. [CrossRef]

18. Glaser, R.; Kiecolt-Glaser, J. Stress-associated immune modulation and its implications for reactivation of latent herpesviruses. Hum. Herpesvirus Infect. 1994, 13, 245.

19. Chen, T.; Song, J.; Liu, H.; Zheng, H.; Chen, C. Positive Epstein-Barr virus detection in coronavirus disease 2019 (COVID-19) patients. Sci. Rep. 2021, 11, 10902. [CrossRef]

20. Paolucci, S.; Cassaniti, I.; Novazzi, F.; Fiorina, L.; Piralla, A.; Comolli, G.; Bruno, R.; Maserati, R.; Gulminetti, R.; Novati, S.; et al. EBV DNA increase in COVID-19 patients with impaired lymphocyte subpopulation count. Int. J. Infect. Dis. 2020, 104, 315-319. [CrossRef]

21. Simonnet, A.; Engelmann, I.; Moreau, A.S.; Garcia, B.; Six, S.; Kalioubie, A.E.; Robriquet, L.; Hober, D.; Jourdain, M. High incidence of Epstein-Barr virus, cytomegalovirus, and human-herpes virus-6 reactivations in critically-ill patients with Covid-19. Infect. Dis. Now 2021, 51, 296-299. [CrossRef] [PubMed]

22. Lehner, G.F.; Klein, S.J.; Zoller, H.; Peer, A.; Bellmann, R.; Joannidis, M. Correlation of interleukin-6 with Epstein-Barr virus levels in COVID-19. Crit. Care 2020, 24, 657. [CrossRef] [PubMed]

23. Singh, V.; Upadhyay, P.; Reddy, J.; Granger, J. SARS-CoV-2 Respiratory Co-Infections: Incidence of Viral and Bacterial CoPathogens. Int. J. Infect. Dis. 2021, 105, 617-620. [CrossRef]

24. Dowd, J.B.; Palermo, T.; Brite, J.; McDade, T.W.; Aiello, A. Seroprevalence of Epstein-Barr virus infection in U.S. children ages 6-19, 2003-2010. PLoS ONE 2013, 8, e64921. [CrossRef] [PubMed]

25. Bauer, G. Simplicity through complexity: Immunoblot with recombinant antigens as the new gold standard in Epstein-Barr virus serology. Clin. Lab. 2001, 47, 223-230.

26. Lam, W.K.J.; Jiang, P.; Chan, K.C.A.; Cheng, S.H.; Zhang, H.; Peng, W.; Tse, O.Y.O.; Tong, Y.K.; Gai, W.; Zee, B.C.Y.; et al. Sequencing-based counting and size profiling of plasma Epstein-Barr virus DNA enhance population screening of nasopharyngeal carcinoma. Proc. Natl. Acad. Sci. USA 2018, 115, E5115-E5124. [CrossRef] [PubMed]

27. Chan, K.C.A.; Woo, J.K.S.; King, A.; Zee, B.C.Y.; Lam, W.K.J.; Chan, S.L.; Chu, S.W.I.; Mak, C.; Tse, I.O.L.; Leung, S.Y.M.; et al. Analysis of Plasma Epstein-Barr Virus DNA to Screen for Nasopharyngeal Cancer. N. Engl. J. Med. 2017, 377, 513-522. [CrossRef]

28. Odumade, O.A.; Hogquist, K.A.; Balfour, H.H., Jr. Progress and problems in understanding and managing primary Epstein-Barr virus infections. Clin. Microbiol. Rev. 2011, 24, 193-209. [CrossRef] 
29. Drago, F.; Herzum, A.; Ciccarese, G.; Parodi, A. May syphilis protect against human papillomavirus infection? An example of heterologous immunity. G. Ital. Dermatol. Venereol. 2019, 154, 719-721. [CrossRef]

30. Spencer, S.A.; Fenske, N.A.; Espinoza, C.G.; Hamill, J.R.; Cohen, L.E.; Espinoza, L.R. Granuloma annulare-like eruption due to chronic Epstein-Barr virus infection. Arch. Dermatol. 1988, 124, 250-255. [CrossRef]

31. Goodlad, J. Epstein-Barr Virus Associated Lymphoproliferative Disorders in the Skin. Available online: https://bit.ly/goodladj1 (accessed on 15 June 2021).

32. Fiorini, G.F.; Sinico, R.A.; Winearls, C.; Custode, P.; De Giuli-Morghen, C.; D'Amico, G. Persistent Epstein-Barr virus infection in patients with type II essential mixed cryoglobulinemia. Clin. Immunol. Immunopathol. 1988, 47, 262-269. [CrossRef]

33. Ichinose, K.; Origuchi, T.; Tashiro, N.; Kawashiri, S.Y.; Iwamoto, N.; Fujikawa, K.; Aramaki, T.; Arima, K.; Tamai, M.; Yamasaki, S.; et al. An elderly patient with chronic active Epstein-Barr virus infection with mixed cryoglobulinemia and review of the literature. Mod. Rheumatol. 2013, 23, 1022-1028. [CrossRef]

34. Rabinowitz, H.K. Infectious mononucleosis presenting as Raynaud's phenomenon. J. Fam. Pract. 1989, 29, 311-315.

35. Blereau, R.P. Idiopathic Raynaud Disease. Consultant360 2013, 194. Available online: https:/ /www.consultant360.com/article/ idiopathic-raynaud-disease (accessed on 15 June 2021).

36. Nirenberg, M.S.; Herrera, M. Foot manifestations in a patient with COVID-19 and Epstein-Barr virus: A case study. Foot 2020, 46, 101707. [CrossRef]

37. Arslan, F.; Karagz, E.; Bekz, H.S.; Ceylan, B.; Mert, A. Epstein-Barr virus-associated haemophagocytic lymphohistiocytosis presenting with acute sensorineural hearing loss: A case report and review of the literature. Infez. Med. 2017, 25, 277-280.

38. Williams, L.L.; Lowery, H.W.; Glaser, R. Sudden hearing loss following infectious mononucleosis: Possible effect of altered immunoregulation. Pediatrics 1985, 75, 1020-1027.

39. Sun, R.; Liu, H.; Wang, X. Mediastinal Emphysema, Giant Bulla, and Pneumothorax Developed during the Course of COVID-19 Pneumonia. Korean J. Radiol. 2020, 21, 541-544. [CrossRef]

40. Fidan, V. New type of corona virus induced acute otitis media in adult. Am. J. Otolaryngol. 2020, 41, 102487. [CrossRef]

41. Lechien, J.R.; Chiesa-Estomba, C.M.; Place, S.; Van Laethem, Y.; Cabaraux, P.; Mat, Q.; Huet, K.; Plzak, J.; Horoi, M.; Hans, S.; et al. Clinical and epidemiological characteristics of 1420 European patients with mild-to-moderate coronavirus disease 2019. J. Intern. Med. 2020, 288, 335-344. [CrossRef]

42. Yang, Y.; Gao, F. Clinical characteristics of primary and reactivated Epstein-Barr virus infection in children. J. Med. Virol. 2020, 92, 3709-3716. [CrossRef] [PubMed]

43. Chimenti, C.; Verardo, R.; Grande, C.; Francone, M.; Frustaci, A. Infarct-like myocarditis with coronary vasculitis and aneurysm formation caused by Epstein-Barr virus infection. ESC Heart Fail. 2020, 7, 938-941. [CrossRef] [PubMed]

44. Chimenti, C.; Russo, A.; Pieroni, M.; Calabrese, F.; Verardo, R.; Thiene, G.; Russo, M.A.; Maseri, A.; Frustaci, A. Intramyocyte detection of Epstein-Barr virus genome by laser capture microdissection in patients with inflammatory cardiomyopathy. Circulation 2004, 110, 3534-3539. [CrossRef] [PubMed]

45. Binkley, P.F.; Cooke, G.E.; Lesinski, A.; Taylor, M.; Chen, M.; Laskowski, B.; Waldman, W.J.; Ariza, M.E.; Williams, M.V., Jr.; Knight, D.A.; et al. Evidence for the role of Epstein Barr Virus infections in the pathogenesis of acute coronary events. PLoS ONE 2013, 8, e54008. [CrossRef]

46. Jaumally, B.A.; Salem, A.; Robinett, K. Epstein-Barr Virus-Related Multisystem Failure in an Immunocompetent Young Man. Crit. Care Med. 2018, 46, 323. [CrossRef]

47. Young, L.S.; Yap, L.F.; Murray, P.G. Epstein-Barr virus: More than 50 years old and still providing surprises. Nat. Rev. Cancer 2016, 16, 789-802. [CrossRef]

48. Hoshino, Y.; Katano, H.; Zou, P.; Hohman, P.; Marques, A.; Tyring, S.K.; Follmann, D.; Cohen, J.I. Long-term administration of valacyclovir reduces the number of Epstein-Barr virus (EBV)-infected B cells but not the number of EBV DNA copies per B cell in healthy volunteers. J. Virol. 2009, 83, 11857-11861. [CrossRef]

49. Verma, D.; Thompson, J.; Swaminathan, S. Spironolactone blocks Epstein-Barr virus production by inhibiting EBV SM protein function. Proc. Natl. Acad. Sci. USA 2016, 113, 3609-3614. [CrossRef]

50. Kotfis, K.; Lechowicz, K.; Drozdzal, S.; Niedzwiedzka-Rystwej, P.; Wojdacz, T.K.; Grywalska, E.; Biernawska, J.; Wisniewska, M.; Parczewski, M. COVID-19-The Potential Beneficial Therapeutic Effects of Spironolactone during SARS-CoV-2 Infection. Pharmaceuticals 2021, 14, 71. [CrossRef]

51. Mareev, V.Y.; Orlova, Y.A.; Plisyk, A.G.; Pavlikova, E.P.; Matskeplishvili, S.T.; Akopyan, Z.A.; Seredenina, E.M.; Potapenko, A.V.; Agapov, M.A.; Asratyan, D.A.; et al. Results of Open-Label non-Randomized Comparative Clinical Trial: “BromhexIne and Spironolactone for Coronsmall a, CyrillicvirUs Infection requiring hospiTalization (BISCUIT). Kardiologiia 2020, 60, 4-15. [CrossRef]

52. Liu, J.; Zhang, S.; Wu, Z.; Shang, Y.; Dong, X.; Li, G.; Zhang, L.; Chen, Y.; Ye, X.; Du, H.; et al. Clinical outcomes of COVID-19 in Wuhan, China: A large cohort study. Ann. Intensive Care 2020, 10, 99. [CrossRef] 